\title{
THE TREND OF MATHEMATICS TEACHING METHOD HAS CHANGE FROM FRAGMENTS TO SYSTEMATICS
}

\author{
Lin $\mathrm{Yi}^{1} \mathrm{Zhou}^{1} \mathrm{Ying}^{1}$ Tommy Tanu Wijaya $^{1}$ \\ ${ }^{1}$ School of Mathematics and Statistics, Guangxi Normal University, Guilin, China \\ Email: 642211654@qq.com
}

\begin{abstract}
According to the school observation in China, There are still fragmentation and superficiality problems in front-line teachers' mathematics teaching method. The reason is that the general system theory has not been rooted in the mathematics teaching method. This study aims to develop Dick-Carey model of systematic design and used in the learning activity. Based on system analysis model, Dick-Carey model of systematic design, and the "Six Questions" cognitive concepts, this paper tries to construct a systematic plan of teaching mathematics. In order to restore the structure, improve the breadth, depth and openness of teaching plan and to promote the systematic model into better teaching method. At the same time, taking the design of "intersecting lines" as an example, this paper explores the effective strategies of systematic design in mathematics teaching.
\end{abstract}

Keywords: Dick-Carey model, Teaching method, Six Questions, Systematic design

In the last ten years, with the continuous development of network information and multimedia technology in the teaching field, a series of concise and new forms of classroom teaching, such as Micro-Course and flipped classroom, has become a hot topic. People pay more attention to the practice and detail knowledge, while disregarding the integrity and the relevant structure of mathematics. After years of research on instructional design by Chinese scholars, it has been found that teachers apply bottlenecks thinking in instructional design, such as split thinking, point thinking and one-directional thinking (Li Zhengtao, 2004). There is a lack of comprehensive understanding that tends to be obvious on the connotation and formalization of instructional design (Xiang Kuihua, 2004). The elements in teaching method are incomplete and less systematic (Hu Dingrong, 2012). The problems with the teaching method are not considering the students need, lack of knowledge generation process and ignoring the basic characteristics of the teaching system (Zhan Zun, Li Mang, You Kaiming, 2006). In general, the perspective of mathematics teaching method is still limited to the several factors and processes, and lacks a strategic position. It fails to design the teaching process in a comprehensive and systematic way, and remains at a fragmented and superficial level. The fundamental reason is that the general system theory cannot be integrated into the design of mathematics teaching.

According to Ministry of Education of the People's Republic of China (2017) The ordinary high school mathematics curriculum standards (2017 edition) pointed out: that "the overall grasp of the teaching content" and the comprehension of mathematics knowledge, strengthens the understanding of mathematics It is necessary to pay attention to the different characteristics, requirements, disciplines, comprehensiveness and integrity of the core literacy of mathematics disciplines.". according to Ministry of Education of the People's Republic of China (2011) The standard curriculum for compulsory education (2011 edition) organises curriculum content along the four main topics which are "number and algebra", "graphics and geometry", "statistics and 
probability" and "synthesis and practice". Emotional attitudes and values show the objectives of the course from four angles, requiring teachers to grasp the integrity of the content and objectives in teaching. These ideas all reflect the thought and significance of general system theory. Therefore, based on the unique characteristics of systemic, abstract, and logical knowledge of mathematics, it is an effective way to promote the systematic theory of mathematics teaching method by systematic thinking. It is also an inevitable trend in conforming to the development of mathematics teaching method.

\section{General System Theory And Teaching System}

In the late 1940s, Ludwig Von Bertalanffy, a Canadian-Austrian theoretical biologist, founded the General System Theory and defined "system" as a complex of several elements in interaction, and proposed "integral indivisibility"."'The theory of the body" and the principle of "holism" have shifted the object of scientific research from the isolated part to the study of the system as a whole (Miao Dongsheng, 2007).. Looking at the material world from the perspective of "system" to reveal the integrity, hierarchy, dynamics and openness of the material system in nature, which coincides with the core of Chinese ancient systemic thinking. The concepts of existence, Yin and Yang, the five elements, the eight diagrams, and the correspondence between heaven and man, which are expounded in ancient Chinese literature always embody rich and profound systematic thoughts such as the Book of Changes, Tao Teh King, Tian Lun, Sun zi's art of war, and so on[8]. From the Treasury of Chinese and foreign systematic thoughts, it can be seen that, just as the implied meaning of "see the trees but not the forest", too much attention is paid to details, parts and scattered individuals while ignoring the overall situation and the connection between its elements.

Teaching is a complex systematic project, and its operational effect is related to the realisation of the quality of education. This paper analyzes the structure and function of each element in teaching based on general system theory, and lays a foundation for the systematic design of teaching.Teaching system is a subsystem of the education system, which is an inseparable whole formed by the interaction of teachers, students, teaching materials and learning environment. Just as the threedimensional structure of the teaching system proposed by professor Yan ZeXian, the teaching system is composed of the teaching element system, the teaching sequence system and the teaching state system (Yan Zexian, Fan Dongping, Zhang Huaxia, 2006). Different system structures have different functions. In mathematics teaching method, it is necessary to organise each element of the teaching system with purpose and benefit, so that the bilateral activities of teaching and learning are in the most possible coordination, and to achieve the optimisation of teaching effectiveness in mathematics teaching.

\section{The Model And Theoretical Basis Of Systematic Design Of Mathematics Teaching}

Instructional design is the combination of systematic methods with psychological theories and instructional principles in an attempt to solve educational and instructional problems (Yan Zexian, Zhang Tieming, 1991). As early as the 1950s and 1960s, the science theory gradually penetrated into 
the field of educational technology and influenced the instructional design. In 1962, Glaser puts forward the concept of "Instructional System", and discussed in detail its connotation and composition (Pi Liansheng, 2009). Along with this, the systematic model of teaching is gradually formed, such as the Dick-Carey systematic design model, the system dynamics model (ISD4) developed by the fourthgeneration instructional system, and the ADDIE instructional design model. Among them, the DikeKerry systematic design model is more suitable for Chinese classroom teaching. This is a model for systematic teaching activities based on the teaching objectives. The summary is to determine the teaching objectives and conduct teaching analysis by determining the behavior, write the teaching specific objectives, design standards test questions reference, develop teaching strategies, develop and select teaching materials, design and implementation formative evaluation, conduct teaching adjustment, design and implementation summary evaluation (Glaser, R, 1962). In recent years, domestic scholars tend to explore the problem of instructional design from a more systematic perspective in order to find a breakthrough to improve teaching efficiency as a whole. For example, professor Ma Lan proposed a holistic and orderly design unit teaching for the teaching thinking of "heavy details and light overall (Dick, W., \& Carey, L. M, 1978). Professor Sheng Qunli put forward the basic model of systematic teaching method with the framework of lesson preparation, class and evaluation (Ma Lan, 2012). However, based on the unique characteristics of systemic, abstract, and logical knowledge of mathematics, how can the general teaching systemization mode be adapted to local conditions in mathematics teaching? This paper combines the teaching practice and related teaching concepts in China, interviews with teaching research experts by members of the research group, references the systematic analysis model through the discussion of the members of the research group, interviewing teaching research experts, first-line teaching classroom observation and other forms, reference system analysis mode, the Dick-Carey systematic design model and the "Six Questions" cognitive concept proposed by professor Zhou Ying, and attempts to build a systematic design model of mathematics teaching, as shown in figure 1.

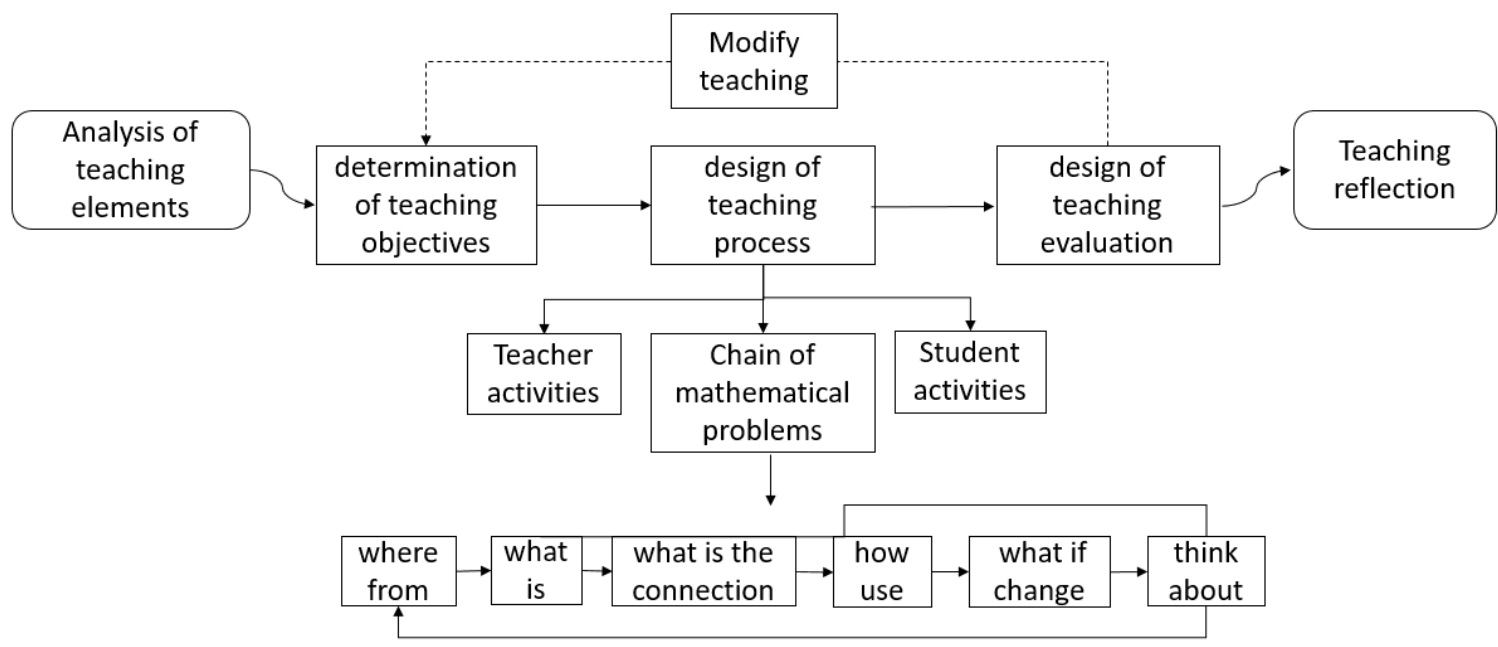

Figure 1. Dick-Carey systematic design model and the "Six Questions" cognitive concept 
Based on Bernice McCarthy's 4MAT teaching model, "Six Questions" is a cognitive methodology created by professor Zhou Ying from the perspectives of problem, operation, refinement and completeness of mathematical knowledge, starting from the coherence of students' thinking and the systematisation of mathematical knowledge. The outline contains six elements of " from where, what is it, what is the connection, how to use, what if it change, and think about" (Sheng Qunli, 2005). "from where": Where does new knowledge of mathematics come from? It mainly involves memory knowledge and situational knowledge. The purpose is to introduce the background source of new knowledge, activate the growth point of new knowledge and aim at the key point of new knowledge. "what is it": What are the essential properties and characteristics of the new knowledge? It mainly involves factual and conceptual knowledge. The purpose is to discover the problem and to grasp the essential characteristics of knowledge, to achieve an understanding of new knowledge. "what is the connection": What are the connections and differences between old and new knowledge or the internal structure of new knowledge itself? It mainly involves the principle and relevance knowledge, which aims to enhance the clarity of knowledge, clarify the structure of mathematical knowledge, and promote the mastery of knowledge. "how to use" : What's the use of the new knowledge, how to use it? It mainly involves procedural knowledge, strategic knowledge and applied knowledge, aim to guide students to apply what they have learned and strengthen the application of mathematical ideas, methods, skills and strategies. "what if it change": What happens if the conditions or conclusions of a mathematical proposition change? What it we solve it with a different method? It mainly involves expanding student's knowledge and methods. The purpose is to explore multiple interpretation, solutions and changeability of knowledge, and to promote the students' innovative and divergent thinking ability. "think about": What did we learn from this lecture? Any other questions? Mainly relates to reflecting the cognitive knowledge. The purpose is to guide the students to review, sort and reflect (Wei Xiaojun, Mo Qianhua, Zhou Ying, 2018). Therefore, "Six Questions" is a mathematical cognitive activity strategy with teachers as the leader, students as the main body, textbooks as the source, problems as the main line, variations as the main strategy and activities as the main force. The cognitive strategy of "Six Questions" provides guidance for efficient design of mathematical problem chain to restore the system structure of mathematical knowledge, and improves the inappropriate situation of general systematic model in mathematics teaching.

Secondly, by referring to the analysis mode of system engineering management, the teaching process is regarded as a system process of "input" and "output". With the idea of system engineering design, the premise of system operation design is to make clear each element of the system and its correlation. This requires us to analyze the teachers, students and teaching contents in the teaching system before designing the teaching process. To understand the teaching foundation, students' cognition and skills reserve, emotional attitude and teaching content requirements. As for the results of teaching after the implementation of teaching method and what needs to be improved, we need to 
make a good teaching reflection plan after the implementation of teaching method, and provide solutions for teaching evaluation and feedback after the teaching implementation. As Professor $\mathrm{Yu}$ Wensen puts forward the effective teaching connotation, the teaching results include teaching effect, effectiveness and efficiency. Specifically, students' academic performance, cognitive change, change of learning attitude, learning to apply, to study, to be an individual and so on. These are all things to consider in our teaching reflection plan (Yu Wensen, 2012). The process of mathematics learning is a continuous and long-term process, which requires teachers to connect the links between various teaching activities with a systematic perspective in instructional design, to ensure that teaching activities connect the past and the future and complete the system structure of mathematical knowledge. The systematic analysis model is designed to improve the narrow view of traditional instructional design confined to one class, enhance the transition between teaching and teaching, and provide a strategic position for instructional design.

\section{Implementation Strategy Of Systematic Design In Mathematics Teaching Intersection Line}

In order to improve the operability of systematic design of mathematics teaching, the author believes that systematic design of mathematics teaching should include the basic links such as teaching factor analysis, goal determination, process design and evaluation design. Taking the design of "intersecting lines" as an example, this paper discusses the effective strategy of systematic design in mathematics teaching.

\section{Analysis of teaching elements}

\section{Analyses of teaching contents}

Based on the curriculum standards, syllabus and different versions of teaching materials, this paper compares and analyses the requirements and presentation of teaching content, in order to prove a reasonable content bases for teaching., As far as the requirements of teaching content are concerned, the Compulsory Education Curriculum Standard requires students to explore and master the basic nature, proof methods and drawing skills of the intersection line in terms of knowledge and skills. In mathematics thinking, it is necessary to study the basis of graphic nature. Further develop the concept of space, and solve the simple practical problems by comprehensively applying mathematical knowledge and methods in solving problems. In emotional attitudes, we must actively participate in mathematical activities, appreciate the value of mathematics and form a rigorous and realistic scientific attitude. It is not difficult to see that the requirements of the curriculum standard for junior high school mathematics learning are not limited to the mastery of mathematics knowledge and skills, but the comprehensive development of students' mathematical literacy. Therefore, teachers should understand the ideological connotation of curriculum standards and implement teaching method in combination with the specific requirements of the syllabus.

In order to understand the similarities and differences in the presentation of teaching contents and avoid and make up for the shortcomings of of the teaching materials, the intersecting lines of different versions of teaching materials can be comprehensively compared from the aspects of content 
arrangement, problem situation, sample exercises, expansion and extension. As shown in figure 2, the knowledge introduction forms of "intersecting lines" in the three editions of textbooks are all different. For example, common life examples are used to arouse students' resonance to "intersecting lines", operation activities are used to let students discover the origin of "intersecting lines", and definition of "intersecting lines" is obtained through observation model. Under the educational background of "multi-edition with a common aim", teachers should not limit themselves to one edition of textbooks, but learn from other editions with an open mind to achieve "teaching with textbooks" instead of "teaching textbooks".

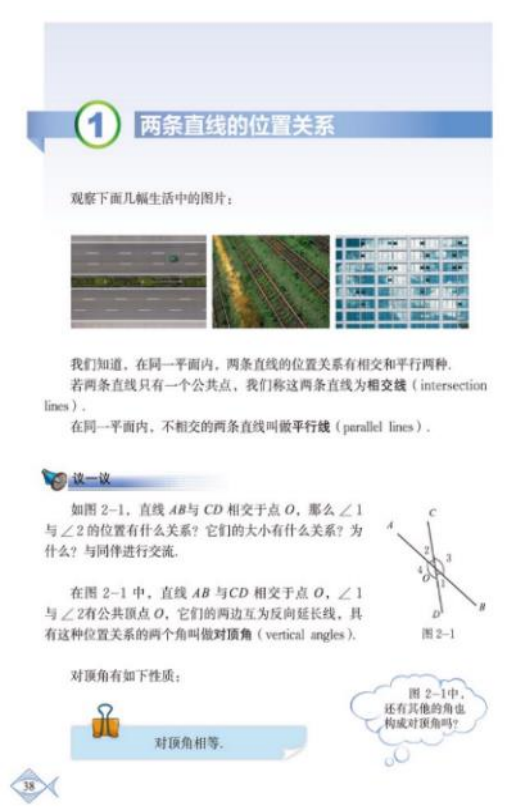

\section{1 相交线}
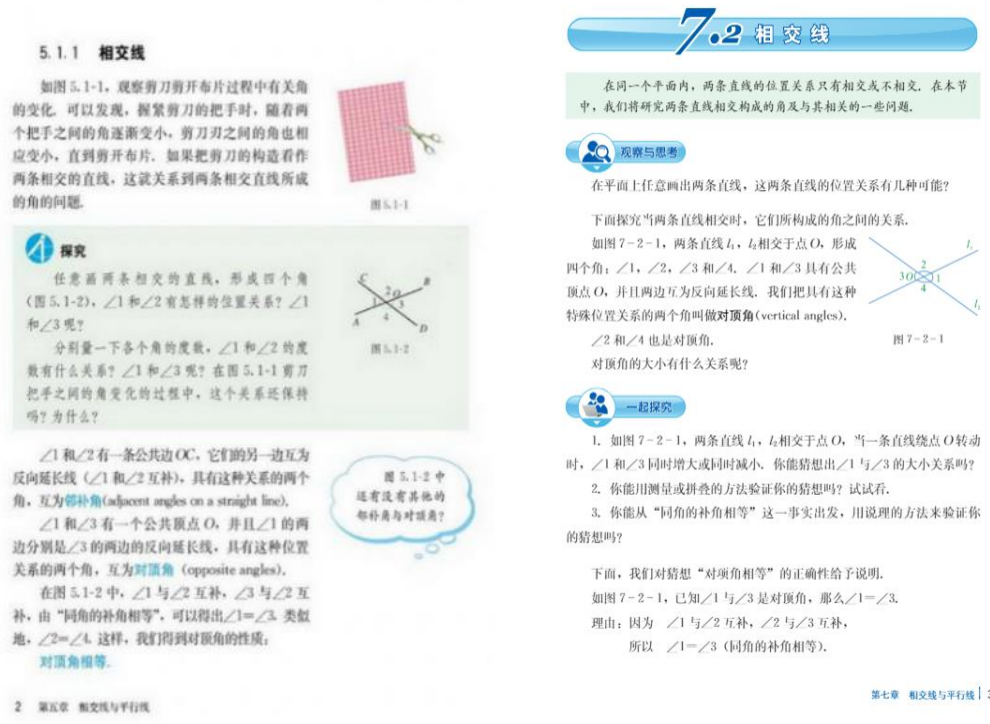

苇境相文线与平行线| 35

Figure 2. Textbook comparison

\section{Student analysis}

As the core element of the teaching system, the teacher understands and grasps the learning status of the students, which provides a reliable basis for the selection of appropriate teaching methods and the adjustment and optimization of teaching method. As for students' learning status, teachers can analyze students' knowledge and skill reserve, emotion and cognitive characteristics. For example, students in primary school have understood the parallel relationship and intersection relationship in combination with the life situation, and will use the complementary Angle, supplementary Angle nature to perform simple operations. They have certain geometric and intuitive qualities, but students still tend to use Intuitive experience to explore geometric knowledge, and does not have the ability to use mathematical knowledge to prove proof of reason

\section{Teacher analysis}

As the implementer of teaching method, teachers' teaching skills and the teaching methods they choose are very important to the success or failure of the implementation of teaching method. However, the analysis itself is often ignored by teachers in the teaching method. For example, what 
kind of teaching skills do teachers have before implementing instructional design? How to use the teaching advantage to improve the teaching, how to make up or improve the teaching insufficiency? Do you have any teaching basis or teaching clues for this class before? How to infiltrate mathematics in teaching? What is the teaching method suitable for students' situation and teaching content, and how to develop it more effectively? These teacher-related teaching problems can become clues for teachers to analyze, provide strong support for teachers to better carry out teaching activities, and lay a foundation for the improvement of teachers' professional qualities.

\section{Determination of teaching objectives}

The determination of teaching objectives should not only reflect the integrity and leadership, but also match the teaching content to reflect the level and operability, which is conducive to the stepby-step completion of the implementation of teaching, as well as the teaching objectives that can be completed by feedback analysis. For example, the teaching objective of "intersecting lines" can be expressed as follows: (1) knowledge and skills: understanding the concepts of adjacent complement angle, apex angle, vertical line, etc., through exploration, operation, reasoning, etc., to explore and grasp the nature of the apex angle. Students can draw a perpendicular line between a point and a line, measure the distance from the point to the line, and correctly identify the corresponding angles, alternate interior angles and same side interior angles. (2) mathematical thinking: In the process of constructing related concepts and properties such as adjacent complement angle, apex angle and vertical line, understanding and using mathematical symbols for reasoning proof, mastering simple reasoning methods, and understanding mathematical symbols are mathematical expressions and mathematics. The form of thinking, improve the ability of mathematical logic reasoning; through observation, drawing and other means to find the basic elements in the basic graphics such as intersecting lines, vertical lines and their relationship, and enhance the concept of space. (3) problem solving: through the process of solving practical problems, students can master the mathematical methods to solve simple geometric problems, develop their awareness of application, and improve their quality of mathematical literacy. (4) emotional attitude and values: through the process of abstracting mathematical models from real life situations, students feel that mathematics comes from life and is applied to life. Through geometric drawing and reasoning, students gradually establish a rigorous scientific attitude.

\section{Design of teaching process}

Teaching process is a process in which teaching contents, teachers and students interact with each other. Therefore, this paper proposes that teaching process should include teacher activity design, student activity and mathematical problem chain. Among them, mathematical problems are the main line of teaching activities and also the bridge connecting teachers and students. The teaching of "intersecting lines" can be divided into three stages. (1) The first stage is to build a general model of intersecting lines -- two lines and four corners. Base on the geometry cognition in primary school, teachers express the concept of intersecting lines by geometric features. Students can recognize the 
adjacent angles and vertical angles by observing the features of the angles formed by intersecting lines, and study the quantitative and positional relations of angles by reasoning. (2) The second stage is to construct a special model of intersecting lines -- perpendicular lines. Students go through the transformation process from intersecting line to vertical line, and have a deep understanding of the concept, symbol representation, drawing method and application of vertical line. In the thinking process from geometric intuition to abstract concept, students are encouraged to form conceptual schema. (3) In the third stage, a complex model of intersecting lines - three lines and eight corners is constructed. With the help of transversals, students have a deep understanding of the logical correlation between corresponding angles, alternate interior angles and side interior angles, and further understand the position relationship between straight lines.

According to the division of teaching process, teachers can reasonably method class hours according to the content requirements of each stage and form a teaching method for each class. In the design of the teaching program, the mathematical problem chain can be designed according to the cognitive concept of "Six Questions", and the arrangement of teachers' activities and students' activities can be carried out with the mathematical problem chain as the main line. For example, in the first stage, the following chain of questions can be designed:

\section{Design of Teaching Process}
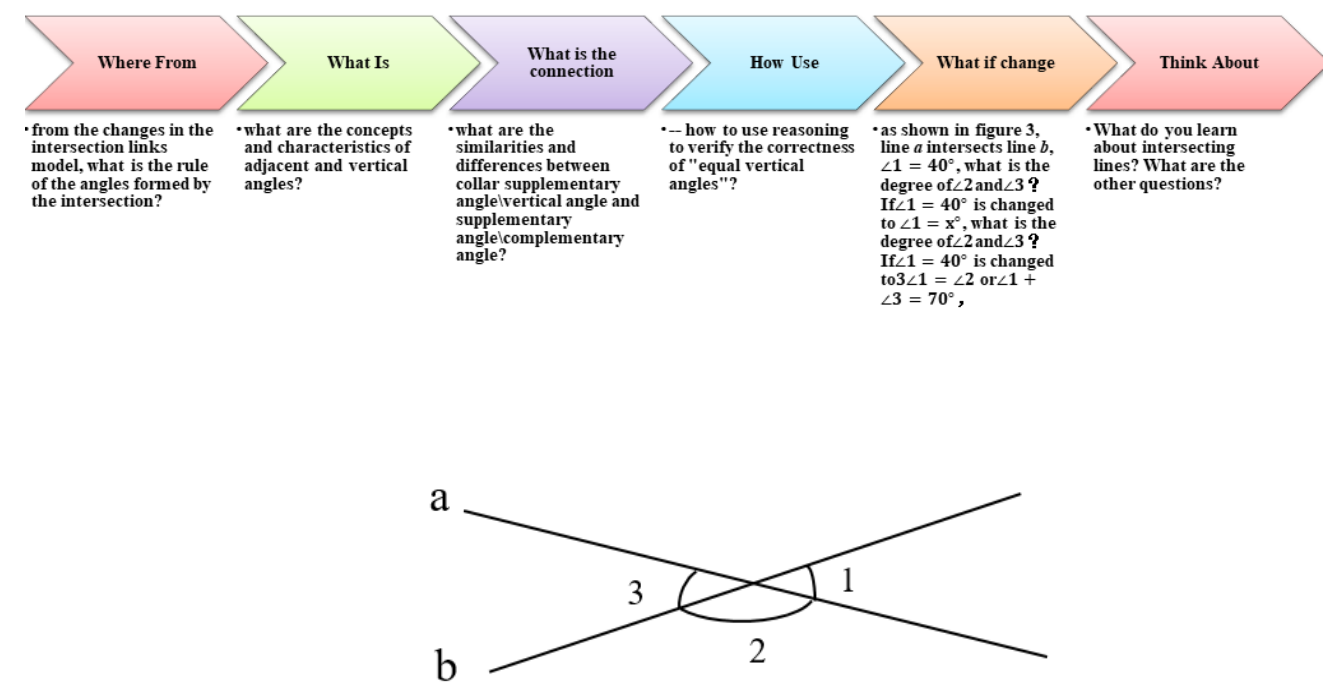

figure 3. teaching process with the "Six Questions" cognitive concept design

\section{Design of Teaching Evaluation}

The focus of evaluation in teaching evaluation design is mainly students' academic achievement. There are various forms of evaluation, including quantitative evaluation such as examination and evaluation, as well as qualitative evaluation such as growth record bag and learning 
experience. In addition to diversified forms of evaluation, the evaluation executor can be diversified and the evaluation type can be integrated. Generally, after the teaching objectives are determined, corresponding evaluation criteria should be formed, and a reasonable teaching evaluation program should be formulated according to the evaluation criteria.

\section{SUMMARY}

Under the background of quality-oriented teaching, the concept of new curriculum standards puts more emphasis on the subject teaching of curriculum content and cultivates students' comprehensive core quality of mathematics in teaching, which requires us to carry out mathematics teaching method from a higher design position. Compared with traditional mathematics teaching method, the systematic design model of mathematics teaching constructed in this paper pays more attention to the effect of systematic thinking guidance in mathematics teaching. This paper analyses the teaching process from the perspective of "jumping out of the system and seeing the system", comprehensively understands the input and output of the teaching system, and broadens the breadth of teaching method. From the perspective of collaborative operation of system elements, the design process with tight coupling is arranged as a whole, and teaching and learning activities are coordinated to expand the depth of teaching method. Based on the characteristics of system function optimization, this paper emphasizes the correction of teaching, breaks the deadlock that teaching method is only floating on the surface, and expands the openness of teaching method. However, there are still some difficulties to be overcome and problems to be solved in teaching practice. For example, do teachers have the time and energy to carry out systematic teaching method under the pressure of completing teaching tasks? How to correct teaching effectively in teaching practice? These problems deserve our further consideration and study.

\section{ACKNOWLEDGEMENT}

We would like to thank to Guangxi Normal University for the research fund which has been given to the researcher. This paper is based from Guangxi in 2019 "Research and Practice of Effective Mathematics Teaching Oriented by Systematic Thinking Ability” (2019JGZ110).

\section{REFERENCES}

Dick, W., \& Carey, L. M. (1978). The systematic design of instruction. Glenview, IL: Scott, Foresman.

Glaser, R. (1962). Psychology and Instructional Technology. Training Research and Education. Edited by Glaser, R. Pittsburgh: University of Pittsburgh Press, pp. 1-30.

Hu Dingrong. (2012). Diagnostic Analysis of Current Primary and Secondary School Teachers' Instructional Design. Curriculum Teaching Research, (7): 11-16.

Li Zhengtao. (2004). The overall consciousness and structural consciousness in contemporary teaching design. Educational Development Research, 2006: 43.

Ma Lan. (2012) Discussion on the teaching of integrated and orderly design unit. Course. Teaching material. Teaching method,(2): 23. 
Ministry of Education of the People's Republic of China. (2017). General Senior High School Mathematics Curriculum Standards (2017 Edition). Beijing: People's Education Press,.

Ministry of Education of the People's Republic of China. (2011). Compulsory Education Mathematics Curriculum Standards (2011 Edition). Beijing: People's Education Press,.

Miao Dongsheng. (2007). Lectures from the University of Systems Science. Beijing: China Renmin University Press: 12-24.

Pi Liansheng. (2009). Instructional Design (2nd Edition). Beijing: Higher Education Press,.

Sheng Qunli. (2005). Teaching Design. Beijing: Higher Education Press.

Wei Xiaojun, Mo Qianhua, Zhou Ying. (2018). The Teaching Design of "Sinusoidal Theorem" Based on the "Six He" Cognitive Chain. Mathematics Learning and Research, 2018(18): 12-13

Xiang Kuihua. (2004). Investigation and analysis of the current situation of teaching design for primary school teachers [J]. Teaching and Management,: 34 .

Yu Wensen. (2012). Three Connotations and Significance of Effective Teaching. Journal of China Education, 2012 (05): 42-46.

Yan Zexian, Fan Dongping, Zhang Huaxia. (2006). Introduction to System Science - Exploration of Complexity. Beijing: People's Publishing House,: 20-24.

Yan Zexian, Zhang Tieming. (1991). Education System Theory. Henan: Henan Education Press,: 41375 .

Zhan Zun, Li Mang, You Kaiming. (2006). Design of Teaching System Based on Complex Adaptive System Thinking. Journal of Electrotechnical Education, (9): 25-29. 